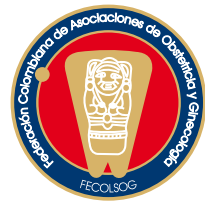

\title{
LA FRAGMENTACIÓN DE ADN ESPERMÁTICO, INFLUENCIA SOBRE LAS TÉCNICAS DE REPRODUCCIÓN ASISTIDA Y LA CALIDAD EMBRIONARIA
}

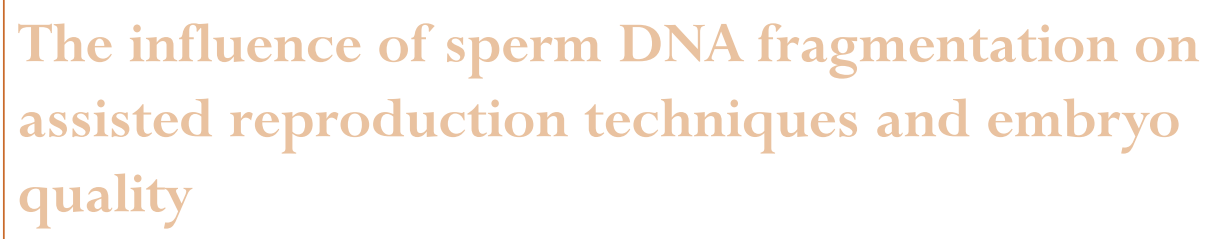

Alfredo Góngora-Rodríguez, M.D.*, Diana Fontanilla-Ramírez**

\section{RESUMEN}

Objetivo: presentar una revisión de la literatura sobre la fragmentación del ADN espermático, su impacto en las técnicas de reproducción asistida y la calidad embrionaria.

Metodología: se utilizó la base de datos MEDLINE/PubMed. Los términos de búsqueda fueron: fragmentación espermática, parámetros seminales, técnicas de reproducción asistida y calidad embrionaria. Se revisaron los artículos publicados entre 1999 y 2010.

Resultados: los estudios de fragmentación espermática proveen información complementaria acerca de la calidad espermática del paciente, siendo una prueba paralela al análisis seminal. Partiendo del diagnóstico de dichas pruebas se puede tomar la decisión acerca de la técnica de reproducción a emplear.

Conclusión: el índice de fragmentación de ADN espermático es una herramienta valiosa para conocer la capacidad fecundante del paciente.

* Centro de Fertilidad Humana en México. México D.F. (México)

** Centro de Fertilidad Humana en México. México D.F. (México)

Universidad del Tolima. Ibagué (Colombia). Correo electrónico:

dfontani@gmail.com
Palabras clave: fragmentación ADN, infertilidad masculina, calidad embrionaria, técnicas de reproducción asistida (TRA).

\section{SUIMMARY}

Objective: presenting a review of the literature about sperm DNA fragmentation, its impact on assisted reproduction techniques and embryo quality.

Methodology: the MEDLINE/PubMed database was searched; the search terms used were: sperm fragmentation, semen parameters, assisted reproduction techniques and embryo quality. Articles published from 1999 to 2010 were reviewed.

Results: sperm fragmentation studies provided complementary information about a patient's sperm quality, this being a parallel test to semen analysis. Such tests' diagnoses represent the starting point for taking decisions about the reproduction technique to be used.

Conclusion: the sperm ADN fragmentation index represents a valuable tool for ascertaining a patient's fertilising ability.

Key words: DNA fragmentation, male infertility, embryo quality, assisted reproduction techniques (ART). 


\section{INTRODUICCIÓN}

La esterilidad afecta a casi un 20\% de las parejas en edad reproductiva. ${ }^{1}$ Este fenómeno afecta a ambos sexos, de tal forma que el factor masculino parece estar involucrado en la mitad de los casos de infertilidad, ${ }^{1}$ por lo que queda fuera de toda duda que el análisis de las características del semen es esencial en la valoración de la pareja con dificultades reproductivas. ${ }^{2}$ A pesar de los datos que brinda el espermograma para evaluar la calidad espermática, se estima que aproximadamente un 10 ó 15\% de los varones estériles presentan parámetros del análisis espermático dentro de rangos normales aunque podrían presentar defectos del ADN de los espermatozoides. ${ }^{3}$ Se ha considerado que el daño del ADN espermático es causa importante de infertilidad y ha despertado particular interés debido al riesgo que implica la transmisión de defectos genéticos a la descendencia, ${ }^{4}$ en especial, cuando se utilizan técnicas de reproducción asistida, donde no es posible realizar una selección espermática que permita excluir espermatozoides con daño en el código genético. ${ }^{3}$ Diversos estudios han demostrado que los espermatozoides humanos exhiben una alta tasa de daño en el ADN y que este se acentúa en condiciones patológicas que conducen a infertilidad. ${ }^{3}$ La transferencia de la molécula del ADN íntegra e intacta desde el espermatozoide al óvulo es crucial para conseguir una fecundación con ciertas perspectivas de éxito. ${ }^{4}$ Por todo lo anterior, se hace indispensable implementar evaluaciones de rutina más exactas como el índice de fragmentación del ADN espermático. ${ }^{4}$

Este documento pretende hacer una revisión sobre las causas, las implicaciones y el impacto de la fragmentación del ADN en la implementación de las técnicas de reproducción asistida.

\section{METODOLOGÍA}

Se realizó una búsqueda en la base de datos MEDLINE/PubMed (http://www.pubmed.com) con los términos: fragmentación espermática, factor masculino, técnicas de reproducción asistida (TRA),
ICSI, azoospermia, embrión, espermatozoide y Halosperm $^{\circledR}$. También se hizo énfasis en la búsqueda de revisiones, guías y protocolos en ScienceDirect (http://www.sciencedirect.com).

\section{RESULTADOS}

\section{Causas del daño del ADN espermático}

La presencia de defectos en el material genético se asocia estrechamente con la infertilidad. Entre estos se cuentan anomalías en la condensación de la cromatina en relación con el proceso de la maduración del espermatozoide, la integridad de la molécula de ADN asociada con la presencia de roturas tanto de doble cadena como de cadena sencilla del ADN, o la presencia de anomalías cromosómicas, como pueden ser las aneuploidías o las reordenaciones genómicas estructurales. ${ }^{4}$

Se sabe que la generación de radicales libres de oxígeno (ROS), ${ }^{5}$ o bien fallos en el intercambio correcto de la fracción histónica de la cromatina por las protaminas, pueden producir daño irreversible en el ADN del gameto. En relación directa con este tipo de acontecimientos, la presencia de apoptosis, como un suceso de muerte celular programada, tiene lugar durante el proceso de maduración espermática. ${ }^{6}$

\section{Técnicas de estudio de la fragmentación del ADN espermático}

Las técnicas que existen para estudiar la fragmentación del ADN espermático se pueden dividir en dos grupos. Un tipo de técnica mide la susceptibilidad diferencial del ADN para ser desnaturalizado por diversos tratamientos (SCSA, DBD-FISH, SCD); el otro tipo de técnicas tiene como fin marcar las roturas en la cadena de ADN (TUNEL, ISNT). Tabla 1.,8

\section{Fragmentación, calidad seminal y potencial fertilizante del espermatozoide}

Se han hallado relaciones entre la fragmentación de ADN y parámetros seminales anormales. En situaciones de oligoteratoastenozoospermia se ha encontrado una mayor fragmentación que en otros casos. ${ }^{2}$ Por otra parte, se ha descrito que la motilidad, morfología y concentración espermática 


\section{Tabla 1. Técnicas que existen para estudiar la fragmentación del ADN espermático.}

\begin{tabular}{|c|c|c|}
\hline Método & Instrumental & Detalles \\
\hline TUNEL & $\begin{array}{l}\text { Microscopio de } \\
\text { fluorescencia, } \\
\text { citometría de flujo }\end{array}$ & $\begin{array}{l}\text { Se incorporan nucleótidos marcados de un fluoro- } \\
\text { cromo en los extremos de las roturas existentes en el } \\
\text { ADN, la reacción se logra con una transferasa termi- } \\
\text { nal, con lo cual se produce una mayor señal en casos } \\
\text { de fragmentación de ADN. }\end{array}$ \\
\hline SCSA & Citometría de flujo & $\begin{array}{l}\text { Se desnaturaliza la molécula de ADN mediante } \\
\text { solución ácida, posteriormente se marca con } \\
\text { naranja de acridina, la cual se intercala entre las } \\
\text { dos cadenas de ADN y la cadena sencilla de ADN } \\
\text { (desnaturalizado) que, a su vez, al ser excitado } \\
\text { emite diferentes longitudes de onda: verde y rojo, } \\
\text { respectivamente. El ADN fragmentado se visualiza en } \\
\text { color rojo al ser más susceptible de desnaturalización. }\end{array}$ \\
\hline $\begin{array}{l}\text { SCD (sperm chromatin } \\
\text { dispersion). } \\
\text { Halosperm }^{\circledR}\end{array}$ & $\begin{array}{l}\text { Microscopio de } \\
\text { fluorescencia, campo claro }\end{array}$ & $\begin{array}{l}\text { Se realiza un tratamiento ácido y desproteinización. } \\
\text { Se forman halos de dispersión de la cromatina según } \\
\text { la formación de bucles de ADN. Si no generan halo, } \\
\text { se considera que el ADN está fragmentado. }\end{array}$ \\
\hline COMETA & $\begin{array}{l}\text { Microscopio de } \\
\text { fluorescencia } \\
\text { electroforesis de ADN }\end{array}$ & $\begin{array}{l}\text { Se incluyen espermatozoides en un microgel de aza- } \\
\text { rosa y se someten a lisis, los núcleos desproteinizados } \\
\text { se someten a electroforesis. El ADN fragmentado } \\
\text { avanza por acción del campo eléctrico y da imagen de } \\
\text { "cometa". }\end{array}$ \\
\hline
\end{tabular}

está alterada en casos de fragmentación de ADN. Estos hallazgos sustentan el hecho según el cual cuando se selecciona un espermatozoide para una técnica de reproducción asistida, se deba considerar que pueda presentar daño en su ADN. ${ }^{9}$ También existen casos en donde los parámetros seminales son normales y se presenta fragmentación de ADN. ${ }^{4,10}$

Por otro lado, en estudios en donde se relaciona la fragmentación y el potencial fertilizante, se encuentra que un índice de fragmentación espermático menor al 15\% tiene excelente potencial, un índice del 15-24\% tiene alto potencial, un índice del 25-30\% tiene bajo potencial y un índice mayor a $40 \%$ tiene muy bajo potencial. Se considera que existe incompatibilidad con la fertilidad in vivo en casos en donde es mayor del 30\%. ${ }^{5}$

De esta manera, en los casos de infertilidad que se reportan como idiopáticos, se podría considerar como causa un índice de fragmentación (DFI) fuera de los parámetros adecuados. ${ }^{9}$ Figura 1.

\section{Impacto del daño en el ADN espermático y los resultados de las técnicas de reproducción asistida (TRA)}

Las técnicas de reproducción asistida se ven comprometidas dependiendo del grado de afectación en el índice de fragmentación espermático, ya que el éxito de estas técnicas radica en la integridad estructural y funcional de los gametos. ${ }^{6}$ Por su parte, los defectos en la cromatina del espermatozoide traen resultados negativos en las técnicas de FIV/ICSI dando lugar a embriones de mala calidad y aborto. ${ }^{5}$ Aunque en estas técnicas se seleccionan los gametos con mejores patrones funcionales, algunos de estos pueden tener defectos en la calidad de la información genética. ${ }^{3}$

En cuanto a la tasa de fertilización, este sigue siendo un tema controversial ya que algunos estudios lo relacionan y en otros no se halla relación con la fragmentación espermática. Pero ante una mayor fragmentación espermática ocurren 
Figura 1. Fragmentación espermática obtenida mediante la técnica de Halosperm ${ }^{\circledR}$, Halotech, España

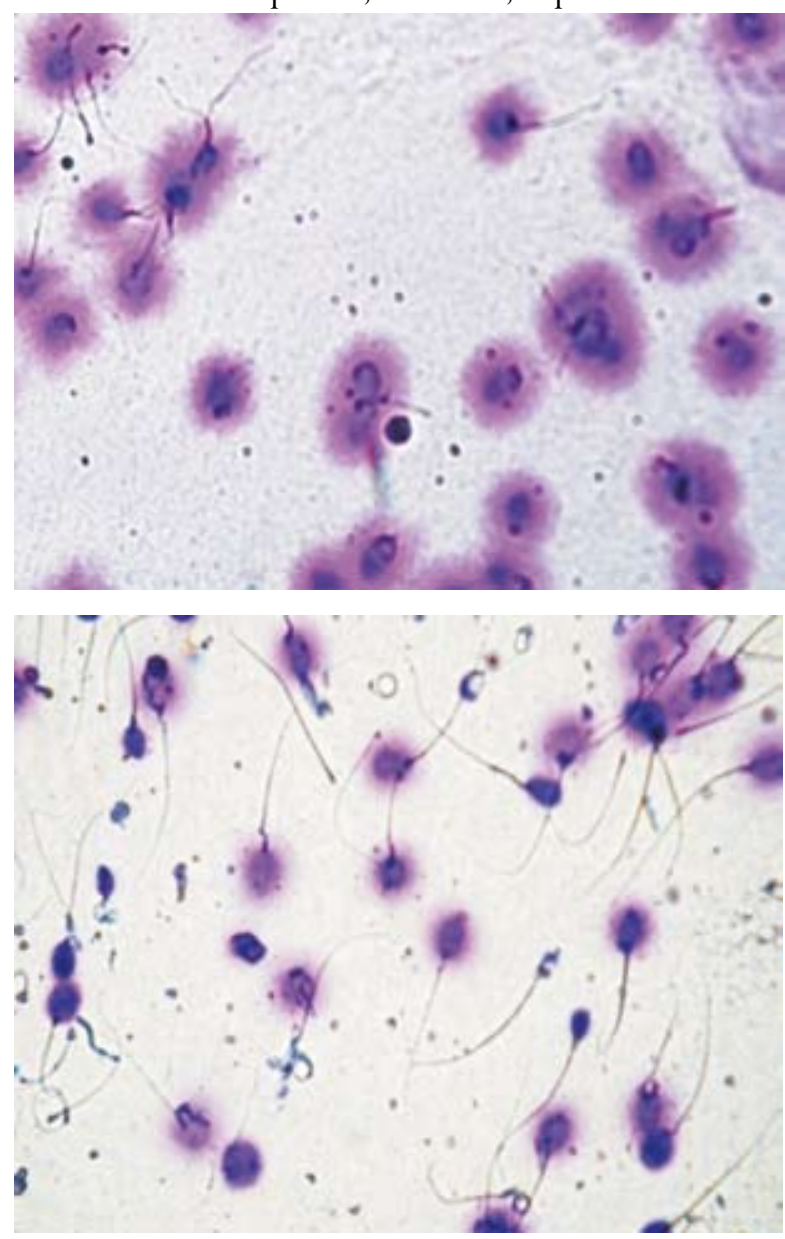

Fuente: Laboratorio Centro de Fertilidad Humana en México.

defectos embrionarios que dan lugar a bloqueos embrionarios y subsiguientes abortos. ${ }^{2}$

En estudios sobre la tasa de embarazo y fragmentación se observó un decremento entre el índice de fragmentación de ADN espermático alto, por encima del 27\%, y la tasa de embarazo en pruebas con técnicas asistidas de fecundación como el FIV/ICSI.

\section{Fragmentación espermática y calidad embrionaria}

La calidad embrionaria se ve estrechamente relacionada con el índice de fragmentación espermática. Se ha reportado que índices de fragmentación entre $>27$ y $30 \%$ conllevan tiempos más largos en lograr concepción, mas ciclos de fertilización in vitro (FIV) e incrementos en la pérdida gestacional. ${ }^{8}$

Los reportes de embarazos logrados por ICSI (inyección intracitoplásmica del espermatozoide), reportan unas tasas bajas de implantación embrionaria (>20\%), estas estarían asociadas probablemente con el daño en el ADN espermático, ${ }^{7}$ igualmente se encuentra ligado a fallas en la fertilización, muerte temprana de embrión, abortos espontáneos, cáncer infantil e infertilidad. ${ }^{7}$

\section{CONCLUISIÓN}

El índice de fragmentación de ADN espermático es una herramienta valiosa para conocer la capacidad fecundante del paciente.

\section{REFERENCIAS}

1. Organización Mundial de la Salud. Manual para análisis seminal; 1999.

2. Morales R, Lledó B, Ortiz J, Rodríguez-Arnedo D, Fabregat A, Bernabeu R. Fragmentación del ADN espermático y su implicación en la fertilidad. Revista Iberoamericana de Fertilidad 2007;24:305-13.

3. Smith R, Kaune H, Pardi D, Madariaga M, Morales I, Ríos R, et al. Aumento del daño en el ADN y estrés oxidativo en espermatozoides de pacientes con oligozoospermia idiopática y antecedentes de criptoquidismo. Rev Méd Chile 2007;135:279-86.

4. Cortés-Gutiérrez EI, Dávila-Rodríguez MI, LópezFernández C, Fernández JL, Gosálvez J. Evaluación del daño en el DNA espermático. Actas Urol Esp 2007;31:120-31.

5. Zini A, Bielecki R, Phang D, Zenzes MT. Correlations between two markers of sperm DNA integrity, DNA denaturation and DNA fragmentation, in fertile and infertile men. Fertil Steril 2001;75:674-7.

6. Zini A, Meriano J, Kader K, Jarvi K, Laskin CA, Cadesky K. Potential adverse effect of sperm DNA damage on embryo quality after ICSI. Hum Reprod 2005; 20:3476-80.

7. Chohan KR, Griffin JT, Lafromboise M, De Jonge CJ, Carrell DT. Comparison of chromatin assays for DNA fragmentation evaluation in human sperm. J Androl 2006;27:53-9. 
8. Fernández JL, Muriel L, Goyanes V, Segrelles E, Gosálvez J, Enciso M, et al. Simple determination of human sperm DNA fragmentation with an improved sperm chromatin dispersion test. Fertil Steril 2005;84:833-42.

9. Avendaño C, Franchi A, Duran H, Oehniger S. DNA fragmentation of normal spermatozoa negatively impacts embryo quality and intracitoplasmic sperm injection outcome. Fertil Steril 2009. In Press.

10. Tomlinson MJ, Moffatt O, Manicardi GC, Bizzaro D, Afnan M, Sakkas D. Interrelationships between seminal parameters and sperm nuclear DNA damage before and after density gradient centrifugation: implications for assisted conception. Hum Reprod 2001;16:2160-5. 